\title{
Artelogie
}

Recherche sur les arts, le patrimoine et la littérature de l'Amérique latine

$4 \mid 2013$

Fêtes et célébrations en Amérique latine

\section{(Em) canto de Santo : Religiosidade e Identidade no Bumba meu boi do Maranhão}

Heridan de Jesus Guterres Pavão Ferreira, Marcelo Nicomedes dos Reis Silva e Claudia Regina Pinto Silva

\section{OpenEdition}

\section{Journals}

Edição electrónica

URL: https://journals.openedition.org/artelogie/6577

DOI: $10.4000 /$ artelogie.6577

ISSN: 2115-6395

Editora

Association ESCAL

Refêrencia eletrónica

Heridan de Jesus Guterres Pavão Ferreira, Marcelo Nicomedes dos Reis Silva e Claudia Regina Pinto Silva, «(Em) canto de Santo : Religiosidade e Identidade no Bumba meu boi do Maranhão», Artelogie [Online], 4 | 2013, posto online no dia 02 fevereiro 2013, consultado o 01 dezembro 2021. URL: http:// journals.openedition.org/artelogie/6577 ; DOI: https://doi.org/10.4000/artelogie.6577

Este documento foi criado de forma automática no dia 1 dezembro 2021.

Association ESCAL 


\title{
(Em) canto de Santo : Religiosidade e Identidade no Bumba meu boi do Maranhão
}

\author{
Heridan de Jesus Guterres Pavão Ferreira, Marcelo Nicomedes dos Reis \\ Silva e Claudia Regina Pinto Silva
}

1 A cultura popular apresenta características que ajudam a definir e delinear um determinado grupo ou segmento social, como é o caso do bumba meu boi, que apresenta variados sotaques, com características peculiares, que se mostram na batida e nas músicas entoadas, denominadas toadas.

2 No estado do Maranhão o bumba meu boi é mais que um folguedo popular que faz parte da vida das pessoas em períodos pontuais do ano, como nos festejos juninos. No estado onde a magia dos tambores mescla ritos e festas, a brincadeira do boi acontece praticamente o ano inteiro, dando-se uma pequena pausa somente por ocasião da quaresma.

3 Mesmo que o bumba meu boi esteja relacionado à música e à dança, chama-se a atenção para o fato que no estado não se dança, mas se brinca boi, sendo que este brincar é uma atividade considerada séria por aqueles que a praticam e que a colocam no patamar da religiosidade e fé.

4 As toadas são cânticos que permeiam a brincadeira do boi e chamam a atenção por diversos aspectos, entre eles, o religioso que se mostra através da devoção aos santos e encantados, haja vista a brincadeira do bumba meu boi girar ao redor de um santo católico ou mesmo de uma entidade que se manifesta nas religiões afro-brasileiras.Os cânticos entoados no bumba meu boi são, portanto, importantes elementos para aferir-se em que medida os valores afrobrasileiros se fazem presentes no contexto da cultura popular, possibilitando a construção de uma identidade étnica. No intuito, pois, de se identificar a presença de elementos que remetem a uma ancestralidade africana presentes nas toadas de bumba meu boi, assim como do diálogo travado entre a literatura e a antropologia das religiões analisou-se alguns cânticos entoados nos diversos sotaques de bumba meu boi, no estado do Maranhão, considerando-se para 
tanto, que é pela linguagem que as pessoas estabelecem relações, impingindo significados tanto a si quanto ao meio em que vivem.

\section{Identidade, literatura e linguagem}

5 Nas últimas décadas tem se intensificado estudos a respeito da identidade mestiça, focando-se principalmente, a questão dos valores identitários afrobrasileiros, que permeiam os sujeitos e suas relações no país, considerando-se para tanto, a contribuição do negro, do branco e do indígena na formação do povo brasileiro.Nessa perspectiva, leva-se em consideração alguns valores identitários, tais como a oralidade, a ancestralidade, a circularidade, entre outros que se manifestam nos usos e costumes do brasileiro, inclusive na cultura popular, citando-se como exemplo as danças circulares tais como o tambor de crioula e o bumba meu boi. Observando-se, pois, um viés entre a literatura e tais valores identitários, buscamos fazer uma relação entre estes e as toadas do bumba meu boi, expressões de arte por meio de palavras, que se manifesta através da literatura, considerando-se para tanto, a literatura enquanto foma de expressar artisticamente por meio de uma linguagem única, refletindo a forma como os grupos representam sua cultura e língua. Nesse sentido, torna-se fundamental que se reconheça o papel da literatura na compreensão global da língua, haja vista tal literatura dizer respeito a um dos domínios da língua. (PAGANINI, 2009).Nesse sentido, verifica-se que a literatura possui uma relação intrínseca com a linguagem, que por sua vez, constitui-se também, forma de ação e de confronto ideológico entre os sujeitos e o meio social. Deste modo, a língua deixa de ser vista como sistema abstrato para ser concebida como um sistema que demarca o social, histórico e o ideológico. Assim, o sujeito, ao enunciar, professa modos de viver em uma realidade social e histórica, demonstrando que ocupa determinadas posições nas relações sociais. (CUNHA, 2008).Verifica-se desse modo, que à língua subjaz uma historicidade que necessita ser considerada, haja vista ser inegável sua transformação ao longo do tempo, pois deve ser considerada sua natureza mutável quanto ao fato desta somente se realizar a partir da interação entre seus usuários. Deste modo o "sentido não é apenas a contraparte do significante, ele é um efeito do aparecimento do significante em condições dadas", que se fazem presentes por meio da literatura. (POSSENTI, 1997).A literatura é então considerada enquanto reserva de cultura, sendo fundamental na formação da pessoa. Ao mesmo tempo, a literatura torna-se produto idealizado de cultura, constituindo-se uma representação da vida, o que ocorre de forma simbólica, refletindo mistérios, o que dificulta certos desvendamentos. (PAGANINI,2009).Nesse sentido, parte-se do pressuposto de que o texto literário não nasce no vácuo, mas a partir de situações concretas, vivenciadas ou não. Deste modo, chama-se a atenção para o fato de não existir texto neutro, pois toda realidade transformada em linguagem é um modo de interpretação e representação da realidade.Segundo Pêcheux (1997) o discurso não surge no vazio, mas remete à formação discursiva que o originou e que é marcada por ideologia ali embutida. Na origem do processo discursivo, há uma formação discursiva permitindo as condições de existência. A escolha lexical, o uso de operadores argumentativos ou a simples escolha do que dizer ou não, infere a intencionalidade do ator social, que se faz possível por meio da literatura. A importância deste trabalho se dá no sentido de que se compreenda alguns fenômenos inerentes à religiosidade, a partir do estudo da linguagem, de modo mais específico, a partir das toadas cantadas 
em homenagem aos santos ou em alusão a encantados e/ou temas da encantaria, toadas estas, entoadas pelos amos ou cantadores de bumba meu boi.

\section{Bumba meu boi e religiosidade}

6 O Brasil é o país da diversidade religiosa, manifestada a partir da contribuição dos vários povos que participaram de sua construção, entre eles, portugueses, indígenas e africanos.A religião católica ou catolicismo é a mais praticada no Brasil e constitui-se um legado dos portugueses que por aqui chegaram, no século XVI, legado este que impingiu uma supremacia da religião mais praticada no país, o cristianismo.o catolicismo, no entanto, teve que conviver com outras religiões, tais quais os ritos praticados pelos índios, assim como as religiões praticadas pelos negros africanos que mais tarde chegaram ao país na condição de escravizados. Os escravos possuíam suas próprias danças, cantos, santos e festas religiosas. Aos poucos, foram misturando os ritos católicos presentes com os elementos dos cultos africanos, na tentativa de resgatar a atmosfera mística da pátria distante.Tal convívio deu origem a um sincretismo religioso que permeia principalmente as denominadas religiões afrobrasileiras, entre elas, o Tambor de Mina, observando-se no interior das articulações entre diferentes religiões relações que ao mesmo tempo são antagônicas e afins.No que diz respeito ao diálogo estabelecido entre as manifestações da cultura popular e a religiosidade, percebe-se uma espécie de necessidade de pedir-se licença, buscando na religião as bênçãos para as brincadeiras se apresentarem. Em relação ao bumba meu boi, ainda que seja por muitos considerada uma brincadeira profana, em razão de ter como figura central um animal (boi), fazendo com que muitos busquem no livro sagrado dos cristãos referenciais contundentes para rechaçá-lo, o bumba meu boi possui um grande viés com a religiosidade, ao que Lima $(1996$, p. 2) comenta que "a 'criação' do Boi corresponde aos arranjos de uma rica variedade de manifestações regilioso-folclóricas ligadas a um substrato do inconsciente coletivo". Viana (2006, p. 31) destaca a ligação do boi com os ritos religiosos, os quais the conferem, na qualidade de vítima ou sacrificado, um caráter sagrado. 0 boi reúne elementos que conduzem a um sincretismo religioso bastante contundente na concepção de S. Ferretti (1997) e, nesse sentido o sincretismo religioso pode ser considerado positivo, uma espécie de celebração entre diferentes religiões, que no caso em tela são : o catolicismo e o Tambor de Mina, considerando-se assim, que a identidade brasileira possui uma grande articulação com o sincretismo, pois, a religiosidade que é intrínseca ao bumba meu boi não diz respeito apenas ao catolicismo popular, mas a uma simbologia e ritos advindos de diferentes e variadas crenças religiosas, oriundas de diversas origens. como enfatiza Sanches (2003, p.12).Observa-se assim, que há uma naturalização do sincretismo que se materializa no bumba meu boi, pois as diferentes religiões convivem de forma harmônica, sem grandes antagonismos, o que ocorre especialmente no tocante à Mina e ao catolicismo.No que concerne ao seu fazer, propriamente dito, chama-se a atenção para o fato do sincretismo despertar sensações antagônicas e de simpatia nas pessoas. Tal sincretismo em razão de não ser individualizado enriquece coletivamente a religião; faz parte das relações que os indivíduos buscam para estabelecerem símbolos e ao mesmo tempo, também faz parte das relações hierárquicas desenvolvidas no âmbito de tais relações. (CARVALHO, 2006, p. 59).S. Ferretti (1997) afirma que o sincretismo se constitui elemento intrínseco a todas as formas religiosas, se manifestando por meio de pagamento de promessas. Procissões ou comemoração a 
um santo. O sincretismo é, portanto, um dos principais focos e o elemnto central das festas religiosas populares. $O$ sincretismo é inerente à religiosidade popular, buscando estabelecer um viés entre o profano e sagrado, o que ocorre claramente no ritual do bumba meu boi. Observa-se isto na abertura de suas atividades, ou seja, o primeiro ensaio geralmente acontece no sábado de aleluia, logo após a quaresma cristã, verificando-se um respeito aos preceitos do cristianismo.

\section{A religiosidade na voz de seus interlocutores}

7 As músicas ou cânticos entoados no bumba meu boi são elementos bastante peculiares, constituindo-se atividade literária em razão de sua forma e conteúdo, descrevendo a realidade a partir da imaginação de seus autores. São cantadas pelos cabeceiras, amos ou cantadores, como são chamados os cantores de boi e geralmente falam de assuntos do cotidiano das comunidades a que pertence cada brincadeira, o que as categorizam enquanto literatura regional.Tais cânticos versam ainda, sobre aspectos da política, mas a maioria aborda temas religiosos, demonstrando sua devoção aos santos e encantados. Prandi (2001, p. 218) discorre sobre a existência de relações de afeto e simpatia que se estabelecem no contexto da religiosidade.Essas relações chamam a atenção principalmente a partir do conteúdo morfosemântico das toadas de bumba meu boi, especialmente no que concerne aos atos das palavras. Cunha $(2008$, p. 9) comenta que os atos das palavras constituem-se suporte para as práticas religiosas, que por sua vez, regulam as eficácias simbólicas. Assim sendo, o universo da oralidade em contextos religiosos vem sendo tomado enquanto objeto de estudos, tendo sua amplitude extrapolado o espaço físico de tendas e barracões e até mesmo das igrejas católicas.o que é dito relaciona-se com o lugar social onde se situam locutores e interlocutores, o que conduz ao conceito de identidade em uma concepção sociológica que segundo (Hall, 2006, p. 12) preenche espaços entre o que vem a ser o mundo pessoal e o mundo público, ou seja, ao "interior" e "exterior".Considerando-se, assim a construção da identidade enquanto um construto social, que é ao mesmo tempo individual e coletivo, torna-se possível observar-se que as toadas do bumba meu boi, foco deste trabalho, são repletas de ideologias haja vista constituírem-se modos de interpretação e representação da realidade daqueles que as cantam. Nesse contexto, insere-se a língua enquanto reflexo da cultura e determinante de formas de pensamento, o código linguístico não apenas reflete a estrutura de relações sociais, mas também a regula. 0 homem aprende a ver o mundo pelos discursos que assimila e, na maior parte das vezes, reproduz esses discursos em sua fala.No que concerne à religiosidade presente no bumba meu boi, esta é observada emo espírito santo vai demonstrar seu poder. Minha vaqueirada! É hora, vou guarnecer. 0 espírito santo vai demonstrar seu poder. Minha vaqueirada! É hora, vou guarnecer. O santo vai nos proteger, o santo vai nos proteger, na hora que eu cantar pra guarnecer.(Bumba-meu boi de Guimarães, sotaque de zabumba)

8 Verifica-se que o cantor anuncia que o espírito santo vai demonstrar seu poder, ou seja, vai abençoar o grupo, chamando seus companheiros (a vaqueirada) para se concentrarem, buscando ainda, convencê-los de que a partir do seu canto, se dará a proteção do altíssimo, em uma clara manifestação de religiosidade e devoção. Outras toadas do bumba meu boi possuem também, um viés com os santos católicos, como se verifica emEu sou patativa da boiada do festejo de S. João/ Eu sou patativa da boiada do festejo de S. João/Junto com meus companheiros, todos me prestam a atenção./ Quem 
tem fé em Jesus Cristo tem a sua proteção.(Bumba-meu boi da Fé em Deus, sotaque de zabumba)

O cantor se intitula patativa da boiada, enaltecendo-se, pois, a patativa é um pássaro de canto maravilhoso, considerado um dos mais belos, entre os cantos de todos os pássaros. Tal enaltecimento se dá de forma dupla, quando este menciona que mais que ser uma patativa, é a patativa do festejo do santo mais reverenciado nas festas juninas. Em seguida, se justifica, dizendo-se protegido pelo fato de ter fé em Jesus Cristo.Chamase a atenção para o fato de que Deus ou seu filho, Jesus Cristo são figuras bastante evocadas no bumba meu boi, além dos santos católicos como São João, São Pedro e São Marçal, como se observa emVou saindo da fogueira que representa uma luz./Eu fiz a minha oração, pedindo a proteção de Jesus./ Ele é mestre dos mestres, professor dos professores, mas pelos nossos pecados morreu pregado na cruz. [...] Lá vai, lá vai meu boi cavando barreira./ Na beira do Rio Jordão, no alto das oliveiras, em homenagem a São João que é o dono da brincadeira.(Bumba-meu boi da Fé em Deus, sotaque de zabumba)

Observa-se na toada acima, a analogia entre o fogo e a luz divina, tendo o autor colocado a fogueira como elemento representativo desta. Em seguida o mesmo pede a proteção de Jesus, enaltecendo suas qualidades como mestre e professor de todos. $\mathrm{O}$ boi é colocado pelo cantador em território sagrado, pois o Rio Jordão é mencionado na bíblia como o lugar onde Jesus foi batizado. $O$ boi também passeia por outro lugar sagrado mencionado na bíblia, o monte das oliveiras. O caminhar do boi, ou sua trajetória, se dá "em homenagem a São João que é o dono da brincadeira", verificando que a despeito de evocar Jesus Cristo e suas qualidades e sofrimentos, o dono da brincadeira é São João, que pela história cristã exerce uma posição menor, hierarquicamente, em relação a Jesus.Aspectos da religiosidade de matriz africana também são observados em toadas de encantados, onde os mesmos muitas vezes usam de um discurso permeado de metáforas para passar sua mensagem, como se nota em Cheguei na fazenda. Era madrugada a hora que o galo cantou.Eu falei pro gado, o touro se levantou. Eu cantei boiada: ei, tchou, ê, tchou. $\mathrm{O}$ meu pai me chama vaqueiro campeador.("Seu” Vaqueiro, encantado)

11 O cantador se apresenta para os demais. Sua chegada na madrugada é uma metáfora, que faz alusão aos mistérios religiosos, que mostram o canto do galo como o anúncio do nascimento de Cristo ou mesmo sinal de augúrio. (DINIZ, 2009). Chama a atenção o fato de que em nossas pesquisas, a toada acima descrita foi colhida durante a brincadeira do boi, quando o cantador está em transe, tendo incorporado o encantado denominado "Seu Vaqueiro", uma entidade da família de Légua-Boji.M. Ferretti $(2008$, p. 9) afirma que o termo encantado é usado no Maranhão[...] nos terreiros de mina, tanto nos fundados por africanos quanto nos mais novos e sincréticos, e nos salões de curadores ou pajés. Refere-se a uma categoria de seres espirituais recebidos em transe mediúnico, que não podem ser observados diretamente ou que se acredita poderem ser vistos, ouvidos ou sentidos em sonho, ou em vigília por pessoas dotadas de vidência, mediunidade ou de percepção extrasensorial, como alguns preferem denominar.

O bumba boi do Maranhão tem raízes ligadas a festejos antes celebrados na Europa, além da sua ligação com a religião, quer seja a oficial (católica na maioria em países como Brasil e México) ou nas religiões ou manifestações religiosas de origem Africana, essa relação não é nova, o que faz com que o mesmo seja considerado folguedo profano. M. Ferretti $(2008$, p. 10) comenta a respeito da relação do bumba meu boi com os santos 
do catolicismo, tendo São João, São Pedro, Santo Antônio e São Marçal como os santos a ele ligados em razão de serem festejados no mês de junho, período em que o boi costuma se apresentar. Outro aspecto que liga a brincadeira do boi à religiosidade é o fato de muitas brincadeiras terem nascido a partir de uma promessa feita a um santo. No caso do "boi de encantado", ou seja, do boi de terreiro, isto decorre para atender a um desejo de uma entidade que geralmente é devota de um santo. Seu desejo algumas vezes é anunciado em sonhos ou vigília. (M. FERRETTI,2008).É muito comum também, entidades se manifestarem na brincadeira do bumba meu boi, entre eles, Seu Vaqueiro, que faz questão de ser reconhecido entre os que compõem o grupo. $O$ cantor/encantado faz questão de ser reconhecido, apresentando-se nominalmente : "O meu pai me chama vaqueiro campeador". Estudos diversos mostram que determinadas entidades são reconhecidas através de suas doutrinas ou no caso do bumba meu boi, das toadas que apresentam algumas características dessas entidades, possibilitando que se faça uma relação com determinadas manifestações culturais. A relação, pois, entre o bumba meu boi e a religiosidade se materializa nas letras de algumas todas, que em determinadas situações se assemelham aos cantos ou doutrinas entoados a santos, entidades e/ou encantados que vivem em reinos da encantaria, ou seja, nos lugares por eles habitados. M. Ferretti $(2008$, p. 6$)$ discorre a respeito da identificação do reino de cada um desses reis e rainhas da Encantaria, que se constituem locais que podem ser identificados no mapa do estado do Maranhão. Assim, destacam-se o porto do Itaqui, as praias da Ponta d' Areia e do Olho d'Água, apresentados enquanto moradias de diferentes encantados, tais como : a Rã Preta, a Princesa Ina e a Menina da Ponta d'Areia. A autora cita ainda a existência de uma passagem no meio da baia, entre duas pedras, localizada entre as cidades de São Luís e Alcântara. Essa passagem é conhecida como Boqueirão e em razão do mar ser muito agitado já foi cenário de diversos naufrágios. Há relatos de que os náufragos foram encantados nesse local. Ainda no meio do mar existe uma rocha conhecida como Pedra de Itacolomi, onde vive a Princesa Doralice, uma das filhas do encantado conhecido como João da Mata ou Rei da Bandeira. A Princesa Doralice teria a forma de uma troirinha.Há relatos de que pessoas teriam se encantado na Praia dos Lençóis, habitada pelo Rei Sebastião, encantado que vive em um reino submerso sob as areias da praia. Outros lugares conhecidos como de encantaria seriam as pontas de Mangunça e de Caçacueira, onde habitam as Mães d'Água de mesmo nome. (M. FERRETTI, 2008).Algumas toadas refletem bem a força dos lugares acima descritos e o que eles representam para o equilíbrio das forças da natureza. Alguns desses lugares são considerados sagrados, tais como a Pedra de Itacolomi, que fica na costa Maranhense na Bahia de São Marcos entre as cidades de São Luís e Alcântara, onde de acordo com relatos, o místico assume contornos e formas, materializando-se. Essa região é conhecida por seus naufrágios, forte e revolta correnteza, que segundo os estudiosos se dá pela grande influência espiritual visto que a Pedra de Itacolomi é reverenciada dentro das religiões afro-brasileiras manifestadas no Maranhão. Na toada "veleiro grande", do Boi de Maracanã, de autoria de Humberto de Maracanã, verifica-se uma espécie de alerta em relação à Pedra de Itacolomi, como pode-se observar emÊ veleiro grande, cuidado com a pedra de Itacolomi/ $\hat{E}$ veleiro grande, cuidado com a pedra de Itacolomi/ Touro Negro anda sobre a maresia/Banzeiro grande eu sempre canto pra ti/ Morro branco de areia, na praia do Carimã/ De lá avistei a sereia na baia de Cumã. (Bumba-meu boi de Maracanã, sotaque de matraca)

13 A toada chama ainda a atenção para o touro negro, que anda sobre a maresia; esse touro representa a entidade denominada Rei Sebastião, que habita, segundo a lenda, os 
Lençóis Maranhenses. Tal entidade alude ao rei português desaparecido em combate e que teria se encantado em terras maranhenses, tendo aparecido em forma de um touro negro na região denominada "Lençóis Maranhenses". o banzeiro grande descrito na toada representa a forte correnteza e a fúria do mar da região. Tal fúria se dá em razão da força do Rei Sebastião que comanda aquelas águas. A relação entre os reis, rainhas, príncipes e princesas e a encantaria é mostrada também na literatura, que apresenta várias histórias sobre reis e príncipes, como por exemplo, as narradas em livreto de cordel, a História do Imperador Carlos Magno e os doze pares de França (BARROS, 1981) que, segundo M. Ferretti (2008, p. 4) foi muito lido tanto no Brasil como em Portugal e que foi base para muitos dos cantadores e poetas populares do Brasil e da literatura de cordel. O livro discorre a respeito das batalhas travadas entre Carlos Magno e doze de seus fiéis vassalos que eram chamados no livro de "os Pares da França" contra os turcos, que eram conhecidos como mouros. Tal leitura desperta a atenção para algumas entidades, citadas em outra toada de Humberto, onde o cantador destaca vários dos chamados reis, nominando-os. Entre os fidalgos ali mencionados está o Rei da Turquia, que é representado por Ferrabrás, que no meio religioso das casas de mina é chamado também de Rei de Alexandria. Na toada de Humberto tem-se uma ideia de quão vasta é a quantidade de reis reverenciados nos cultos religiosos, isso sem falar nos santos que representam entidades de religiões de origem africanas. Observemos na toada como Humberto versa sobre os Reis da encantaria, evocando-os e louvando-os Salve os terreiros que o pai oxalá mandou/Turquia, Casa das Minas e a Casa de Nagô. Viva Deus ! Viva as Rainhas e os Reis da Encantaria! Rei Badé, Rei Verequete/ O Rei da Alexandria. Rei Guajá, Rei Surrupira, Rei Dom Luís, Rei Dom João.Rei dos feiticeiros, dos Exus e Rei Leão. Rei Oxossi, Rei Xangô, Rei Camungá, Rei Xapanã e Barão Rei de Guaré. Protejam o Boi do Maracanã, Rei da Bandeira, o Rei da Maresia, Rei de Itabaiana, salve o Rei da Bahia.E os Reis que eu não falei em verso, falo no meu coração. Salve o Rei dos Índios. Salve o Rei Sebastião.(Bumba-meu boi de Maracanã, sotaque de matraca)

Inicialmente, o cantor saúda os terreiros ou casas de culto afro, chamando a atenção para o reino da Turquia, evocado no Tambor de Mina e também para a Casa das Minas e Casa de Nagô, duas das mais tradicionais e antigas casas de cultos, situadas na cidade de São Luís, capital do estado do Maranhão. Em seguida, o cantador dá vivas a Deus, em uma espécie de respeito a uma divindade hierarquicamente superior, chamando em seguida, os reis e rainhas da encantaria, nominando-os um a um. Chama-se a atenção para o fato de que mesmo sem especificar a que deus se refere, o cantador o invoca em primeiro plano, reverenciando-o, observando-se que ao não especificar o deus saudado na toada, o poeta deixa aberto à interpretação do ouvinte, para que este o defina a partir de sua crença. Paganini $(2009$, p. 4$)$ comenta que em razão da literatura, em razão de sua qualidade de obra de arte, constitui-se produto de efeitos de comunicação onde o interlocutor possua sensibilidade, constituída a partir de sua própria cultura para apanhar a mensagem que lhe é destinada. Verifica-se desse modo, que o poeta busca no interlocutor, uma espécie de diálogo, onde um se reconhece no outro, identificando-se e ao mesmo tempo, estimulando-lhe a busca de relações com o que acredita. Chamam, pois, a atenção o conteúdo morfosemântico presente nos cânticos do bumba meu boi, especialmente no que concerne aos atos das palavras. Cunha $(2008$, p. 9) comenta que os atos das palavras constituem-se suporte para as práticas religiosas, que por sua vez, regulam as eficácias simbólicas. O que é dito relaciona-se com o lugar social onde se situam locutores e interlocutores. Por ser a língua um reflexo da cultura e determinante de formas de pensamento, o código linguístico não apenas reflete a 
estrutura de relações sociais, mas também a regula. $\mathrm{O}$ homem aprende a ver o mundo pelos discursos que assimila e, na maior parte das vezes, reproduz esses discursos em sua fala.

\section{Considerações finais}

15 A religião, as celebrações, as rezas, orações, toadas são formas de se manter tradições e culturas. O bumba boi do Maranhão consegue fazer isso com muita propriedade, em seus mais diversos sotaques, entre estes o sotaque de matraca ou mesmo o de zabumba, descritos neste trabalho.As toadas de bumba meu boi, de variados sotaques, constituem-se elementos intrínsecos à literatura, por meio das quais as pessoas dizem de si e do mundo a sua volta.Seja no sotaque de matraca, seja no sotaque da baixada ou no sotaque de Zabumba ou de Guimarães, o sobrenatural e o misterioso se materializam, por meio das diferentes expressões que compõem a cultura do estado do Maranhão, um caldeirão de manifestações que vai do tambor de crioula ao tambor de mina, da dança do coco ao Cacuriá, do bumba-meu- boi de matraca ao de costa de mão.A cultura do Maranhão e do Brasil ganha muito por manter vivas tradições que começaram muito além das fronteiras geográficas dos estados Brasileiros. Tal cultura é responsável também, pela construção de identidades e preservação de elementos relacionados à tradição africana e afro-brasileira e se mostra entre outros, através dos cânticos entoados no bumba meu boi. o universo da literatura oral, apresentado em uma perspectiva da religiosidade é importante elemento para compreensão dos valores afrobrasileiros, assim como da construção de identidades, haja vista sua amplitude extrapolar o espaço físico de tendas e barracões e até mesmo das igrejas católicas, invadindo espaços de manifestações da cultura popular, como o bumba meu boi.

\section{BIBLIOGRAFIA}

BARROS, Leandro G. A batalha de Oliveiros com Ferrabrás e a Prisão de Oliveiros. Juazeiro do Norte : [s.n.]. 1981. Folheto de Cordel.

CARVALHO, Maria Michol Pinho de. O Bumba meu boi no Maranhão. Superintendência de Cultura Popular do Maranhão, 2006. Disponível em : http://www.culturapopular.ma.gov.br

CUNHA, Ana Stela de A. (2008)- "Si to lo nfumbe ta sere sere : traços de línguas crioulas em mambos e mpuyas em Palo Monte (Cuba)". Africana Studia, Centro de Estudos Africanos da Universidade do Porto, n. 11, pp 161-183.

DINIZ, Vânia. (2009). O galo e suas contradições. Disponível em : HYPERLINK 'http:// www.vaniadiniz.pro.br/' http://www.vaniadiniz.pro.br/.

FERRETTI, M.. Encantados e encantarias no folclore brasileiro. Trabalho apresentado no VI Seminário de ações integradas em Folclore. São Paulo, 2008. 
FERRETTI, Sérgio. O sincretismo afro brasileiro e resistência cultural. Trabalho apresentado na Mesa Redonda Reafricanização e Sincretismo no V. Congresso Afro-Brasileiro realizado em Salvador entre 17 e 22 de agosto de 1997.

HALL, Stuart. A identidade cultural na pós-modernidade, DP\&A Editora, $1^{a}$ edição em 1992, Rio de Janeiro, 11ª edição em 2006, 102 páginas, tradução : Tomaz Tadeu da Silva e Guacira Lopes Louro). LIMA, Carlos de. Boi de Zabumba. Comissão Maranhense de Folclore. Boletim nº 5. São Luis, 1996.

PAGANINI, Martanézia Rodrigues. Literatura e representação da identidade cultural : reflexão sobre o ensino de leitura na sociedade da representação. ALB, E S, v. 2, n.2, p. 12-16, jan./abr 2009. PECHEUX, M. Semântica e discurso : uma crítica à afirmação do óbvio. $2^{\text {a }}$ ed., Campinas : Editora da Unicamp, 1997.

POSSENTI, Sírio. Sobre as noções de sentido e de efeito de sentido. (Versão revisada do texto :) Notas sobre a noção de efeito de sentido. Estudos lingüísticos : Anais de Seminário do GEL. XXVI. Campinas, Unicamp-FAPESPGEL,-727, 1997.

PRANDI, Reginaldo - Encantaria Brasileira : o livro dos mestres, caboclos e encantados. Editora Pallas, São Paulo, 2001.

SANCHES, Abmalena. (2003). É de fé e devoção o brinquedo da ilha : a religiosidade no bumba meu boi. Boletim n. 26 da Comissão Maranhense de Folclore. Disponível em : HYPERLINK 'http:// www.cmfolclore.ufma.br/x/bol...' http://www.cmfolclore.ufma.br/x/bol....

VIANA, Raimundo Nonato Assunção. Corpo, estética e dança popular : situando o bumba meu boi. UFRN, Natal, 2006.

\section{RESUMOS}

Este trabalho enfoca as toadas cantadas no bumba meu boi do Maranhão, enquanto importante elemento para construção de identidades e preservação dos valores culturais afrobrasileiros, que se materializam por meio de um diálogo entre a religiosidade e a literatura.

This paper focuses about the melodies sung in the Bumba meu boi in Maranhão, as an important element for the construction of identity and preservation of Afro-Brazilian cultural values, which possibility a dialogue between religion and literature.

\section{ÍNDICE}

Keywords: religion, Bumba-boi, identity

Palavras-chave: religião, Bumba-boi, identidade

\section{AUTORES}

\section{HERIDAN DE JESUS GUTERRES PAVÃO FERREIRA}

Doutoranda em Informática na Educação, UFRGS, Graduada em Letras pela Universidade Federal do Maranhão/UFMA, professora Assistente da mesma universidade e Pesquisadora do grupo de Linguagens, cultura e identidades - UFMA. Brincante do Bumba meu boi da Fé em Deus. 


\section{MARCELO NICOMEDES DOS REIS SILVA}

Professor - Rede pública de ensino do Estado do Maranhão. Graduado em Letras - Universidade Federal do Maranhão ; Mestrando em Educação e Pesquisador da Cátedra Unesco de Juventude, Educação e Sociedade - Universidade Católica de Brasília e do grupo de Linguagens, cultura e identidades da UFMA. Brasilia, DF - Brasil.nicomedes@gmail.com

\section{CLAUDIA REGINA PINTO SILVA}

Professora Especialista, SEDUC/MA, Historiadora 